\title{
Preliminary studies on some waste vegetable contribution to the soil fertility
}

\author{
Elisabeta CHIRILA ${ }^{\mathrm{a}}$, Naliana LUPASCU* ${ }^{\mathrm{b}}$ and Simona RAICU ${ }^{\mathrm{a}}$ \\ ${ }^{a}$ Department of Chemistry and Chemical Engineering, Ovidius University from Constanta, \\ 124 Mamaia Blvd, 900527 Constanta, Romania \\ ${ }^{\mathrm{b}}$ Pedological and Agrochemical Studies Office, 17-19 Revolutiei Street, 900735 Constantza, Romania
}

\begin{abstract}
Researches on the use of waste vegetable (tomatoes, peppers) and fruits (apples, plums) in order to improve the nutritional quality of the soil have been performed. The content in nitrogen, phosphorus, potassium, humus, organic matter have been analyzed in fruits and vegetable waste and also in soil before and after mixing with each waste at a ratio of 1:2.5. Analyses were done by using current analytical methods (chemical and absorption molecular spectrometry) after previous mineralization of samples with appropriate reagents. To investigate the effect of vegetable wastes on the plants growth, wheat has been planted in the witness soil sample and in the mixed soil with wastes. The nutrients concentration in vegetable waste was higher than in fruit waste (33-75\%). Available phosphorus concentration increased about two times in soil with fruit waste while in the soil with vegetable the increase was of about 3 times. Potassium concentration increased about three times in soil mixed with both types of waste. Although potassium and organic matter have higher values in the soil amended with fruit waste than in the witness soil, the height of the wheat was similar with those in the control soil due to the limiting role of phosphorus.
\end{abstract}

Keywords: vegetable wastes, soils, phosphorus, potassium, nitrogen, humus, organic carbon

\section{Introduction}

Soil fertility is a complex process that involves the constant cycling of nutrients between organic and inorganic forms. As plant material and animal wastes decompose, they release nutrients to the soil solution. Food wastes, which include damaged fruit and vegetable, together with other biodegradable organic wastes represent a valuable source of secondary raw materials [1]. Possible uses of organic wastes are as fertilizer and soil amendment, the production of dietary fibers [2] or animal fodder and as a source of energy [3-5].

Agricultural activity in general and the production of fruits and vegetables in particular produce large quantities of crop residues and byproducts. Composting these wastes and / or products can help to reduce waste production. On the other hand, the compost product can be distributed on the surface of the culture and can therefore contribute to improve the physical and chemical properties of the soil [6-7, 11-12].

Fruit and vegetable wastes used for agricultural purposes could assure the following advantages:

(i) providing necessary nutrients to plant growth; nutrient release is gradual and compost making it represents a permanent source of fertilizer; (ii) improving soil structure and increasing its resistance to erosion; (iii) there is no need to use chemical fertilizers, protecting us from their effects once they are in our body through fruits and vegetables; (iv) reducing the volume of waste stored in the landfill with the immediate effect on the environment protection; (v) is basically getting free fertilizer; (vi) protects the soil from the effects of extreme temperatures $[6,7]$.

The study aims to report preliminary results on the use of some waste vegetable (tomatoes, peppers) and fruits (apples, plums) in order to improve the nutritional quality of the soil. 


\section{Experimental}

The investigations have been carried out in Corbu village, Constanta County. To obtain vegetable wastes, 3 kilograms of each vegetable: tomatoes (Lycopersicon esculentum) and peppers (Capsicum annuum), and fruits: apples (Malus domestica) and plums (Prunus domestica) have been left for six months from June to December 2012 in colorless vessels in natural climatic conditions. Six months after, crop residues were chopped and then mixed in a ratio of 1:2.5 with garden soil. In the soil samples with wastes and in the witness soil it has been sowed wheat (Triticum aestivum) and the growth and development of the wheat it has been followed by measuring the plants' height.

To observe the influence of waste on soil fertility the following soil characteristics were determined: $\mathrm{pH}$, total nitrogen, total phosphorus, potassium, organic matter, humus.

There were analyzed samples of the witness soil (1), the fruit wastes (2) the vegetable wastes (3), the mixture of soil with the vegetable wastes and of soil with the fruit wastes before and after the wheat growth: soil mixed with fruit wastes before the growth of the wheat (4); soil mixed with fruit wastes after the growth of the wheat (5); soil mixed with vegetable wastes before the growth of the wheat (6) and soil mixed with vegetable wastes after the growth of the wheat (7).

The analytical methods applied for samples characterisation were those currently used in soil science laboratories [8-10]; the mineralization of the samples for the determination of total nitrogen and phosphorus was carried out with the equipment Turbotherm which reduced the working time.

Available phosphorus and potassium concentration from soil samples have been extracted using calcium acetate-lactate solution (P/AL and K/AL) [11].

\section{Results and Discussions}

\subsection{Agrochemical characterisation of the unfertilized soil}

The table 1 presents the obtained results concerning the unfertilised soil analytical characterisation and the description of its supply status.

Table 1 Witness soil characterization

\begin{tabular}{|c|c|c|}
\hline Parameter, UM & Value & Supply status \\
\hline $\mathrm{pH}$, units & 8.2 & Weak alcaline \\
\hline P-AL, ppm & 143.09 & Very good \\
\hline K-Al, ppm & 530 & Very good \\
\hline Humus, \% & 2.83 & Middle \\
\hline $\begin{array}{c}\text { Total } \\
\text { nitrogen, } \\
\%\end{array}$ & 0.138 & Middle \\
\hline $\begin{array}{c}\text { Organic } \\
\text { matter, \% }\end{array}$ & 9.5 & Very low \\
\hline
\end{tabular}

\subsection{Nutritional characteristics of wastes}

Table 2 shows the concentration of nutrients in the investigated fruit and vegetable waste compared with the same characteristics of the materials used as natural fertilizers (compost and manure).

It could be noted that the studied wastes have important nutritional potential and high nutrient concentrations (nitrogen, phosphorus and potassium) due to the chemical composition of raw materials.

Therefore it is expected that the addition of organic waste as fertilizer lead to improved nutritional qualities of the soil.

Table 2 Nutrients concentration in studied vegetable wastes versus literature data about other organic fertilizers

\begin{tabular}{|l|c|c|c|c|}
\hline $\begin{array}{c}\text { Parameter, } \\
\text { UM }\end{array}$ & FW & VW & C & M \\
\hline TN, \% & 2.47 & 3.65 & 0.3 & $0.7-2.0$ \\
\hline TP, \% & 0.3 & 0.4 & 0.3 & $0.3-1.2$ \\
\hline Potassium, \% & 3.06 & 5.38 & 0.3 & $0.8-0.9$ \\
\hline
\end{tabular}

TN - total nitrogen; TP- total phosphorus; FW - fruit waste; VW - vegetable waste; $\mathrm{C}$ - compost obtained from different organic sources; $\mathrm{M}$ - manure.

\subsection{Study of the wheat growing in the soil with wastes samples}

It was found that in all three series of pots (control soil, soil with fruit waste and soil with vegetable waste) wheat germinated in five days. Ten days after germination, wheat in the pots with fruit 
waste was $4 \mathrm{~cm}$ (mean value), the same as in the control pots and in the pots of vegetable waste had a height of $6 \mathrm{~cm}$ (mean value). After 15 days was observed the same difference in height of $2 \mathrm{~cm}$ for the wheat grown in soil with vegetable waste (12 $\mathrm{cm})$ and grown in soil with fruit waste $(10 \mathrm{~cm})$ which was the same level as in the control pots (Fig.1).

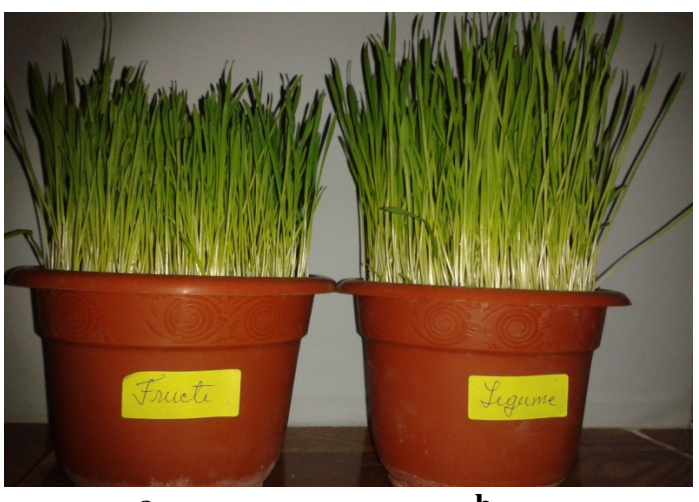

b

Fig.1. Comparative height of the wheat plants cultivated in soils mixed with fruit waste (a) and with vegetable waste (b).

\subsection{The influence of the soil fertilization with fruit} waste and vegetable waste on the soil characteristics

The analytical data regarding the concentration of the available phosphorus and potassium extracted in calcium acetate-lactate (P/AL and K/AL) in the investigated samples are presented in Fig. 2 and Fig.3.

There is an increase in the intake of nutrients as follows:

- Phosphorus concentration showed a significant increase (about two times) in the soil with fruit waste before wheat growing, while in the soil with vegetable the increase was of about three times.

- Potassium concentration showed a significant increase (about three times) in soil mixed with both types of waste (vegetable waste and fruit waste).

This increase is due to the organic fertilizers' intake of assimilate nutrients and to their positive effect on the physical and chemical properties of soil [8].

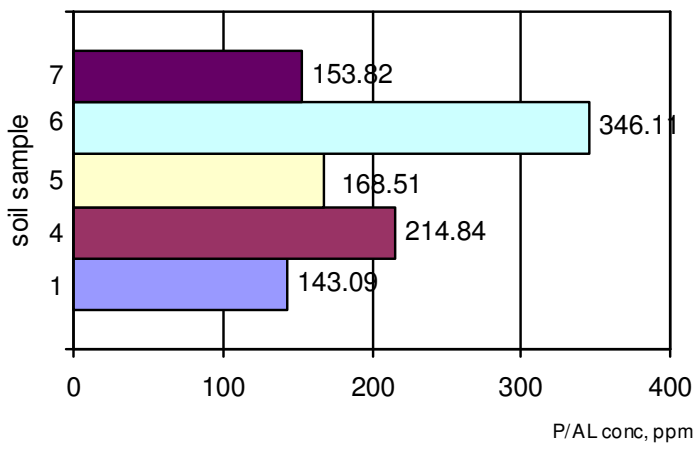

Fig.2. P/AL concentration (ppm, mean values) in analysed samples: 1 - control soil; 4 - soil mixed with fruit wastes before the growth of the wheat; 5 soil mixed with fruit wastes after the growth of the wheat; 6 - soil mixed with vegetable wastes before the growth of the wheat; 7 - soil mixed with vegetable wastes after the growth of the wheat.

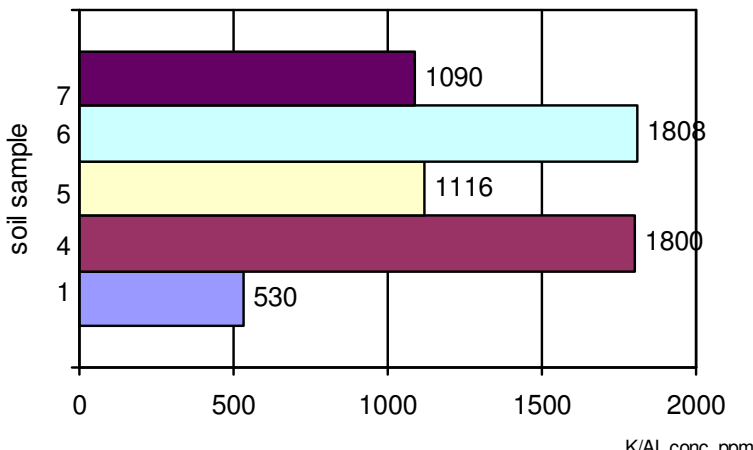

Fig. 3. K/AL concentration (ppm, mean values) in analysed samples: 1 - control soil; 4 - soil mixed with fruit wastes before the growth of the wheat; 5 - soil mixed with fruit wastes after the growth of the wheat; 6 - soil mixed with vegetable wastes before the growth of the wheat; 7 - soil mixed with vegetable wastes after the growth of the wheat.

To understand the causes of change in soil humus content is useful the concept that describes organic matter as the main repository of chemical energy in photosynthesis related to plant and its 
associated entropy. Humus contributes strongly to the occurrence of fertility and to the soil's production capacity. Table 3 presents the obtained results concerning the parameters of which depends the soil fertility (humus, total nitrogen, and organic matter) in analysed samples before and after the growth of wheat.

Humus content increased significantly from $2.83 \%$ to $4.90 \%$ to the application of organic fertilizer from vegetable waste and from 2.83 to $4.35 \%$ to the application of organic fertilizer from the fruit waste. Humic substances are exposed to oxidative degradation till the stable compounds; the released energy together with some of the intermediate products are used in the metabolism of soil microorganisms $[9,10]$.

Table 3. Humus, total nitrogen and organic matter concentration in the investigated samples

\begin{tabular}{|c|c|c|c|}
\hline Sample & $\begin{array}{c}\text { Humus } \\
\%\end{array}$ & $\begin{array}{c}\text { Total } \\
\text { nitrogen } \\
\%\end{array}$ & $\begin{array}{c}\text { Organic } \\
\text { matter }\end{array}$ \\
\hline 4. & $\mathbf{4 . 3 5}$ & $\mathbf{0 . 2 1}$ & $\mathbf{1 1 . 0 0}$ \\
\hline 5. & 3.91 & 0.19 & 10.50 \\
\hline 6. & $\mathbf{4 . 9 0}$ & $\mathbf{0 . 2 4}$ & $\mathbf{1 5 . 0 0}$ \\
\hline 7. & 4.62 & 0.22 & 11.00 \\
\hline
\end{tabular}

Rational application of organic fertilizers has important implications for nutrient content, humus and soil organic matter which leads to higher crop yields in terms of quality and quantity.

\section{Conclusions}

The aim of the performed experiments was to study the contribution of fruit and vegetable waste on soil fertility. The obtained results show the following:

(i) The nutrients concentration in vegetable waste was higher than in fruit waste;

(ii) After applying vegetable waste to soil, increased values of all nutrients concentrations have been observed, while the fruit waste only increases the concentration of nitrogen and potassium in soil;

(iii) The content of humus and organic matter in the soil has been significantly improved under the influence of the studied fruit and vegetable wastes; (iv) The obtained analytical results have been confirmed experimentally by the more vigorous growth of the wheat in the soil amended with waste vegetable. Although potassium and organic matter have higher values in the soil amended with fruit waste than in the witness soil, the growth of the wheat was similar with those in the control soil. The explanation consists in the limiting role of phosphorus that in the case of fruit waste is equal to the concentration in the control soil.

\section{References}

* E-mail address: naliana_lupascu@yahoo.com

[1]. J.Angulo, L. Mahecha, S. A. Yepes, A. M. Yepes, G. Bustamante, H. Jaramillo, E. Valencia, T. Villamil and J. Gallo, Journal of Environmental Management 95, S203-S209 (2012)

[2]. J. Lin, J. Zuo, R. Ji, X. Chen, F. Liu, K. Wang and Y. Yang, Journal of Environmental Sciences 24(7) 1288-1294 (2012)

[3]. H. Bouallagui, Y. Touhami, R. Ben Cheikh and M. Hamdi, Process Biochemistry 40 989-995 (2005).

[4]. A.Nawirska and M. Kwasniewska, Food Chemistry 91, 221-225 (2005)

[5]. Y. Jiang, S. Heaven and C.J. Banks, Renewable Energy 44, 206-214 (2012)

[6]. T. Nemeth, O. Palmai and J. Horvath in Role of fertilizers in sustainable agriculture - Proceedings (Ed. C. Hera, E. Schnug, M. Dumitru, A. Dorneanu), Bucharest, 2001, pp. 55-61

[7]. C. Hera, A. Popescu and V. Mihaila in Soil fertility and the future of agriculture in Europe (Ed. C. Hera, C. Kleps), The Publishing House of the Romanian Academy, Bucharest, 2006, pp. 25-38

[8]. N.Lupascu, G.Popa and I.Tintisan, Ovidius Univ. Annals of Chem. 22, 67-70 (2011)

[9]. M. Nicolaescu, N. Lupascu and E. Chirila, Environmental Engineering and Management Journal 8 (4) 911-914 (2009).

[10]. M. Nicolaescu, N. Lupascu and E. Chirila, Ovidius University Annals of Chemistry 18 (2), 171173, (2007)

[11]. N.J Njukeng, E.G. Nkeng, E.E. Ehabe and E Schnug, International Research Journal of Pure \& Applied Chemistry 3(1), 22-31 (2013)

[12]. M. Rus, M. Marghitras, T. Mihaiescu, I. Oroian and A. Dumitras - Agrochemistry (In Romanian), Ceres, Bucharest, 2005

[13]. R. Lacatusu - Agrochemistry (In Romanian), Terra Nostra, Iasi, 2006

Submitted: May $3^{\text {th }} 2013$

Accepted in revised form: November $21^{h} 2013$ 